Dermatology 2011;223:122-123

DOI: $\underline{10.1159 / 000329432}$

\section{Is the Distance Enough to Eradicate in situ or Early Invasive Subungual Melanoma by Wide Local Excision? From the Point of View of Matrix-to-Bone Distance for Safe Inferior Surgical Margin in Koreans}

Jun Young Kimª, Han Jin Jung a , Weon Ju Leea , Do Won Kima, Ghil Suk Yoon ${ }^{b}$, Dong-Sun Kim ${ }^{c}$, Mae Ja Parkc, Seok-Jong Lee

Departments of ${ }^{\mathrm{a}}$ Dermatology, ${ }^{\mathrm{b}}$ Pathology and ${ }^{\mathrm{C}}$ Anatomy, Kyungpook National University School of Medicine, Daegu, Republic of Korea

Key Words

Matrix-to-bone distance $\cdot$ Subungual melanoma, Koreans • Surgical margin $\cdot$ Wide local excision

We read with interest a paper published in a recent issue of Dermatology [1], in which Duarte et al. emphasize the necessity of conservative surgical management in nail matrix melanoma in situ. The authors included early invasive melanoma, as well as in situ melanoma, in the indication for conservative surgical management. Since Hutchinson first described subungual melanoma
(SUM) in 1886, a radical surgical strategy has been recommended as a dogma for the treatment of SUM $[2,3]$. However, recently SUM has often been managed by conservative surgery such as wide local excision (WLE) and grafting, with which good results were achieved [4-6]. Moreover, Moehrle et al. [7] also proved that functional surgery is superior in terms of cure and survival and that the 2 independent poor prognostic factors are melanoma thickness and amputation.

However, from the point of view of a safe inferior surgical margin, there are some points to consider. Haneke [8] had studied the distance between the tip of the nail matrix and the extensor tendon insertion of the middle finger of a young male adult on the aspect of surgical anatomy of the nail apparatus, in which the measured distance was $0.8 \mathrm{~mm}$. Considering a little more practical aspect of the inferior surgical margin, we measured the shortest actual distance between the lowest base of the nail matrix and the phalangeal bony surface (fig. 1) in 15 Korean cadavers to confirm the safety of the conservative surgical management like WLE and grafting to treat SUM after permission from the Department of Anatomy of Kyungpook National University School of Medicine. As shown in table 1 , the mean distances were $0.90 \mathrm{~mm}(0.51-$ $1.50 \mathrm{~mm}$ ) for 1st fingers (14 specimens), $0.72 \mathrm{~mm}(0.27-1.20 \mathrm{~mm})$ for 5th fingers (13 specimens), $0.87 \mathrm{~mm}(0.46-1.30 \mathrm{~mm})$ for $1 \mathrm{st}$ toes (13 specimens) and $1.09 \mathrm{~mm}(0.40-1.65 \mathrm{~mm})$ for 5 th toes (13 specimens). The average distance of all digits was $0.90 \mathrm{~mm}$, and the shortest distance among the specimens we measured was $0.27 \mathrm{~mm}$.

Table 1. The matrix-to-bone distances ( $\mathrm{mm}$ ) measured in the 15 cadavers

\begin{tabular}{|c|c|c|c|c|c|c|c|}
\hline No. & Date of death & Age, years & Sex & 1st finger & 5th finger & 1st toe & 5 th toe \\
\hline 1 & April 28, 2006 & 68 & $\mathrm{~F}$ & 0.69 & 0.57 & 0.78 & 0.70 \\
\hline 2 & August 9, 2006 & 51 & $\mathrm{M}$ & 1.25 & 0.70 & 1.30 & 1.48 \\
\hline 3 & August 14, 2006 & 44 & $\mathrm{M}$ & 0.96 & 0.46 & 0.46 & 0.79 \\
\hline 4 & September 13, 2006 & 74 & $\mathrm{~F}$ & 0.67 & 0.50 & 1.28 & 1.48 \\
\hline 5 & September 18, 2006 & 56 & M & 1.13 & 0.96 & 0.91 & 1.05 \\
\hline 6 & October 25, 2006 & 70 & $\mathrm{M}$ & 1.50 & 1.10 & 0.80 & 1.65 \\
\hline 7 & October 25, 2006 & 41 & $\mathrm{M}$ & 1.03 & 1.20 & 1.00 & 1.10 \\
\hline 8 & February 15, 2007 & 55 & $\mathrm{~F}$ & - & - & 0.69 & 0.71 \\
\hline 9 & February 26, 2007 & 46 & $\mathrm{M}$ & 0.92 & 0.68 & - & 0.84 \\
\hline 10 & March 5, 2007 & 59 & $\mathrm{~F}$ & 0.75 & - & 0.97 & - \\
\hline 11 & May 3, 2007 & 51 & $\mathrm{M}$ & 0.72 & 0.27 & 0.87 & - \\
\hline 12 & May 4, 2007 & 47 & M & 0.51 & 0.31 & - & 0.40 \\
\hline 13 & June 15, 2007 & 57 & M & 1.03 & 0.81 & 1.18 & 1.60 \\
\hline 14 & August 14, 2007 & 64 & $\mathrm{~F}$ & 0.64 & 0.71 & 0.58 & 1.20 \\
\hline 15 & February 25, 2008 & 73 & $\mathrm{~F}$ & 0.86 & 1.08 & 0.54 & 1.18 \\
\hline \multicolumn{2}{|c|}{ Average } & 57.1 & & 0.90 & 0.72 & 0.87 & 1.09 \\
\hline
\end{tabular}

\section{KARGER}

(๑) 2011 S. Karger AG, Basel
Fax +4161306 1234 E-Mail karger@karger.ch www.karger.com 

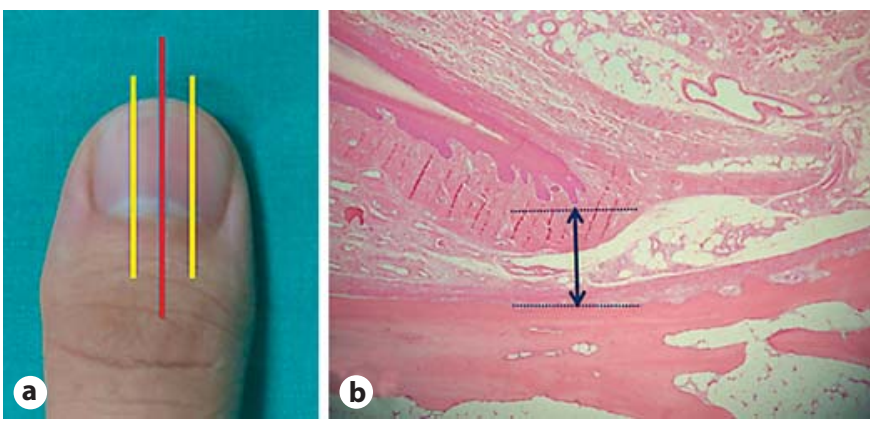

Fig. 1. a Both lateral parts of the digits, along the yellow lines, were trimmed for better bone fixation and measured for matrix-tobone distance at the middle line (plane) of the nail along the red line. $\mathbf{b}$ Shortest distance from the lowest base of the nail matrix to the phalangeal bony surface, not to the periosteal surface (distance between the two horizontal dotted lines). HE. $\times 200$.

Though the amputation for SUM had been a dogma for decades, functional loss and bad cosmetic outcome of digits after amputation have made patients prefer conservative management. However, according to Haneke's [8] and the present study, WLE does not seem to be sufficient for eradication of invasive SUM regarding the safe inferior margin, because of the paucity of the subungual soft tissue between the tumor and the bone beneath the nail apparatus. Moreover there is a possibility of presence of an undetected thicker area of melanoma than the identified thickness with one routine biopsy or a few biopsies, which can consequently change the surgical strategy. Lastly, so-called 'skeletization' may not be so easy, and some soft tissue adherent to bone can remain after WLE. In conclusion, the WLE procedure which has a good functional and cosmetic outcome in the majority of patients needs to be carefully employed for the treatment of early invasive melanoma due to the paucity of the subungual soft tissue between the tumor and the bone beneath the nail apparatus until a consensus is made for the safe inferior surgical margin, which is expected to be established by further studies.

\section{Acknowledgment}

This work was supported by a grant of the Korean Ministry of Education, Science and Technology (Regional Core Research Program/Antiaging and Well-Being Research Center).

Disclosure Statement

No conflict of interest declared.

\section{References}

1 Duarte AF, Correia O, Barros AM, Azevedo R, Haneke E: Nail matrix melanoma in situ: conservative surgical management. Dermatology 2010;220:173-175.

2 Pack GT, Oropeza R: Subungual melanoma. Surg Gynecol Obstet 1967; 124:571-582.

3 Daly JM, Berlin R, Urmacher C: Subungual melanoma: a 25-year review of cases. J Surg Oncol 1987;35:107-112.

4 Imakado S, Sato H, Hamada K: Two cases of subungual melanoma in situ. J Dermatol 2008;35:754-758.

5 Ishihara Y, Matsumoto K, Kawachi S, Saida T: Detection of early lesions of 'ungual' malignant melanoma. Int J Dermatol 1993;32:44-47.

6 Smock ED, Barabas AG, Geh JL: Reconstruction of a thumb defect with integra following wide local excision of a subungual melanoma. J Plast Reconstr Aesthet Surg 2010;63:e36-e37.

7 Moehrle M, Metzger S, Schippert W, Garbe C, Rassner G, Breuninger $\mathrm{H}$ : 'Functional' surgery in subungual melanoma. Dermatol Surg 2003; 29:366-374.

8 Haneke E: Surgical anatomy of the nail apparatus. Dermatol Clin 2006; 24:291-296.

Seok-Jong Lee, MD

Department of Dermatology

Kyungpook National University School of Medicine

Samduk 2ga, Jung-gu

Daegu 700-721 (Republic of Korea)

Tel. +82 53420 5837, E-Mail seokjong@knu.ac.kr 